\title{
Educação Permanente em Saúde: Como e em que espaços se realiza na perspectiva dos profissionais de saúde de Porto Alegre
}

Loiva dos Santos Leite. Secretaria Municipal da Saúde de Porto Alegre.

Kátia Bones Rocha. Pontifícia Universidade Católica do Rio Grande do Sul.

\section{Resumo}

O artigo parte de uma tese de doutorado e apresenta a perspectiva de profissionais da Rede de Atenção Psicossocial (RAPS) de Porto Alegre no que diz respeito a como e em que espaços é possível realizar Educação Permanente em Saúde (EPS). Trata-se de uma pesquisa qualitativa, para a qual foram entrevistados vinte e quatro sujeitos através de entrevistas semiestruturadas. Utilizou-se análise temática e os resultados foram organizados nas categorias como e espaços. Como refere modos de promover EPS e espaço remete a uma configuração que reflete a dinâmica que o produziu. Como fazer se conforma em algum espaço seja concreto, simbólico ou engendrado a partir de determinadas necessidades. Capacitações, cursos, seminários, reuniões de equipe, matriciamento, cotidiano dos serviços e fóruns da RAPS sintetizam os dados referidos pelos sujeitos. Concluiu-se que os espaços de EPS podem promover conexões entre diferentes profissionais e práticas, reforçando diálogos e articulações através do como fazer. Palavras-chave: educação permanente em saúde; saúde mental; rede de atenção psicossocial.

\begin{abstract}
Permanent education in health: How and in which spaces it is performed in the perspective of healthcare professionals of Porto Alegre. The paper is part of Phd tesis and presents the view of professionals from a Psychosocial Care Network (PCN) in Porto Alegre regarding to how and in which areas it is possible to implement a Permanent Health Education (PHE). This is a qualitative study, for which twenty-four subjects were interviewed through semi-structured interviews. A thematic analysis was used to assess the results, organized in categories how and spaces. How refers to ways of promoting EPS and space refers to a setting that reflects the dynamics that it has produced. How to do it conforms in some space be it concrete, symbolic or engendered from certain requirements. Training, courses, seminars, team meetings, matricial, everyday services and PCN forums synthesize the data reported by subjects. It was concluded that the PHE spaces can promote connections between different professionals and practices, strengthening dialogue and bonds through how to do.
\end{abstract}

Keywords: permanent health education; mental health; network of psychosocial care.

\section{Resumen}

Educación continuada en salud: Como y en que espacios se realiza, a partir de la perspectiva de profesionales de salud de Porto Alegre. El artículo es parte de una tesis de doctorado y presenta la perspectiva de los profesionales de la Red de Atención Psicosocial (RAPS) de Porto Alegre, con respecto a cómo y en qué espacios es posible desarrollar la Educación Continuada en Salud (ECS). Se trata de un estudio cualitativo en el cual fueron entrevistados veinticuatro profesionales a través de entrevistas semiestructuradas. Se utilizó el análisis temático y los resultados fueron presentados a partir de las categorías: Cómo y Espacio. El Cómo se refiere a las formas de promover ECS y el Espacio se refiere a la configuración y la dinámica que lo produce. El Cómo hacer se configura en concreto, simbólico o engendrado a partir de determinadas necesidades. Formación, cursos, seminarios, reuniones de equipo, apoyo del equipo especializado y los foros de RAPS sintetizan los datos que los profesionales mencionaron. Se concluyó que los espacios ECS pueden promover las conexiones entre los diferentes profesionales y prácticas, el fortalecimiento del diálogo y las articulaciones a través de cómo hacerlo.

Palabras clave: la educación sanitaria permanente; salud mental; la red de atención psicosocial. 
A Educação Permanente em Saúde (EPS) foi instituída como política pública pelo Ministério da Saúde em 2007, tendo como proposta a "aprendizagem no trabalho, onde o aprender e o ensinar se incorporam no cotidiano das organizações e ao trabalho" (Portaria $\mathrm{n}^{\circ}$ 1.996/2007, p. 6). A aprendizagem é feita a partir da problematização das questões vivenciadas nos cotidianos do trabalho em saúde, favorecendo a aproximação do profissional com as realidades locais e suas diferentes demandas.

A EPS se constitui como um recurso importante para fomentar mudanças nos processos de trabalho, especialmente no que diz respeito à atenção em saúde mental, devido às especificidades éticas, técnicas e políticas que a definem como um campo em permanente reconfiguração. Com as diretrizes da Reforma Psiquiátrica, lei vigente no Brasil desde 2001 (Lei n. 10.216, de 6 de abril de 2001), gradativamente começam as transformações no modelo assistencial e, com isso, as mudanças no modo de operar o cuidado para as pessoas com sofrimento psíquico.

Pitta (2011) analisou o processo da Reforma Psiquiátrica passados mais de uma década da implementação da Lei n. 10.216. Refere que muito se avançou com a redução de leitos em hospitais psiquiátricos, com a criação e ampliação de serviços como Centros de Atenção Psicossocial (CAPS) e Serviços Residenciais Terapêuticos, voltados para a desinstitucionalização das pessoas submetidas a longas internações psiquiátricas (Pitta, 2011). Corroborando com essa perspectiva, Macedo, Abreu, Fontenele e Dimenstein (2017) apontam que as mudanças decorrentes do processo da Reforma contribuíram para a expansão de serviços extra hospitalares, territoriais e comunitários, ampliando a cobertura assistencial em saúde mental no Brasil, inclusive em cidades de menor porte. A regionalização e a descentralização da atenção são fatores que têm contribuído para fortalecer a atenção integral e em redes (Macedo et al., 2017).

Um avanço importante para consolidação das diretrizes da Reforma Psiquiátrica foi a implementação, em 2011, da Rede de Atenção Psicossocial (RAPS) através pela Portaria 3088/2011, destinada à atenção de pessoas com sofrimento psíquico. A RAPS preconiza serviços articulados em rede, garantindo acesso e a integralidade do cuidado (Lei n. 10.216, de 6 de abril de 2001). A RAPS consolida a desinstitucionalização das políticas de saúde mental em um modelo de tratamento aberto, público, com equipes multidisciplinares e serviços de intervenção em diferentes níveis de complexidade (Amarante, Oliveira, Torre, \& Coelho, 2016).

Todavia, alguns pontos críticos repercutem nesse contexto, como por exemplo, a dificuldade em romper com o modelo manicomial, persistindo a coexistência de serviços asilares e substitutivos, assim como as práticas profissionais centradas na "objetificação do portador de sofrimento psíquico", nos "especialismos", nas "demandas por internação" e na descontinuidade do cuidado (Macedo et al., 2017, p. 156). Outro aspecto levantado pelos autores, diz respeito ao foco do processo da Reforma direcionado para o fechamento de leitos e para a reinserção social de pessoas institucionalizadas, sendo que outros grupos ficaram, por muito tempo, sem visibilidade para as ações de cuidado em saúde mental, como os usuários de drogas, população de rua, situações de violências, entre outros.

Dentre os desafios da Reforma Psiquiátrica Brasileira, Vasconcelos (2012) aponta a importância do movimento incorporar a discussão sobre economia política, que considere os desdobramentos do contexto neoliberal no sucateamento das políticas sociais, no qual as possibilidades da Reforma Psiquiátrica abrangente e bem-sucedida, com suporte intersetorial, diminuem efetivamente.

É notório que ainda há muito trabalho a ser feito para a consolidação do cuidado integral em saúde mental, especialmente em relação aos vazios assistenciais, à integração dos pontos de atenção da rede (Macedo et al., 2017) e a superação do estigma que envolve as pessoas com sofrimento psíquico (Pitta, 2011).

Em relação ao estigma e à mudança no processo de cuidado às pessoas com sofrimento psíquico, Tenório (2002) destaca duas importantes ações a serem feitas: a oferta de uma rede de cuidados que ajude os usuários a viverem na comunidade e a construção de novas atitudes da sociedade em relação aos doentes mentais. Amarante (2007) e Delgado (2011) assinalam que as mudanças fazem parte de processos que exigem constante investimento a fim de que se modique as relações entre a sociedade a loucura. Amarante et al. (2016) referem que o movimento Reforma Psiquiátrica brasileira inclui os direitos humanos no campo da saúde mental considerando aspectos tanto da luta contra violência, na busca da extinção de manicômios, como também a luta pela promoção de direitos humanos, a partir do reconhecimento da diversidade dos sujeitos com sofrimento psíquico ou vulnerabilidade social. 
Nesse cenário complexo, a Reforma tem se constituído na conjunção de resistências, desejos e embates. Em função disso, é preciso avançar, tanto em relação à promoção da autonomia dos usuários e seus familiares como protagonistas desse processo, quanto em relação à atenção e cuidado que os profissionais precisam realizar no cotidiano dos serviços de saúde. Nesse contexto, destacamos a importância da EPS como uma possibilidade para compor esse processo de mudanças na atenção em saúde mental, como uma "estratégia político-pedagógica", remetendo os profissionais à reflexão acerca do seu processo de trabalho, oportunizando a "aprendizagem significativa - a aprendizagem que produz sentido para o sujeito" (Sarreta, 2012, p. 3). A aprendizagem significativa favorece a interseção entre o fazer e os efeitos que esse aprendizado produz, ou seja, o cuidado deixa de ser um ato repetitivo e protocolar e passa a estabelecer a busca por uma relação igualitária. Nessa perspectiva, o trabalho pode "ser o lugar de atuação crítica, reflexiva, propositiva, compromissada e tecnicamente potente", provocando transformações e ampliando a capacidade de cuidado integral em saúde no Sistema Único de Saúde (SUS) (Ceccim, 2005a, p. 976).

Justificamos importância de compreender a EPS na medida em que o "sujeito do conhecimento se produz em meio às práticas sócio-históricas", como escrevem Aguiar e Rocha (2007, p. 650). É ao vivenciar e experenciar as situações cotidianas e sua complexidade, em diferentes espaços, que o conhecimento pode ser construído, retratando a realidade e as necessidades que o mundo do trabalho em saúde apresenta.

Ao falarmos sobre espaços entendemos que precisamos nos situar acerca de que perspectiva estamos nos referindo, pois podemos encontrar definições em várias áreas do conhecimento como arquitetura, geografia, sociologia, política, economia, entre outras. Iremos nos ater às perspectivas que possam contribuir com a discussão proposta em nosso estudo. Uma leitura inicial que pode ser feita acena que espaço pode ser concebido como lugar físico criado "através de práticas sociais e processos materiais que servem à reprodução da vida" (Harvey, 2007, p. 189).

No campo da saúde, Pessatti e Carvalho (2009) definem espaço físico "como um território vivencial de relações interpessoais, onde as pessoas vivem, convivem, se relacionam, trabalham e que é construído num processo histórico, político, econômico e social" (p. 74). Para Haesbaert (2014) a noção de espaço pode ser compreendida a partir das suas relações de poder, em sua dinâmica de construção e reconstrução permanente. Portanto, em movimento e extrapolando a noção de algo delimitado. Desse modo, espaço refere-se a algo amplo que envolve aspectos concretos e subjetivos, pois diz respeito aos lugares em que a vida das pessoas acontece, logo, um espaço dinâmico.

Como promover EPS aponta na direção da construção coletiva dos processos de cuidado e de gestão em saúde, envolvendo os diferentes atores. Os comos podem ser a partir de algumas ferramentas metodológicas como Reuniões de Equipe, Matriciamento, Fóruns, Rodas de Conversa e, ainda o "relato da produção do cuidado realizado com um usuário" tomado como "Usuário-guia" (EPS em Movimento, 2014, p. 1). No contexto dessa pesquisa, essas ferramentas dialogam entre si, inclusive interpondo-se e, ao mesmo tempo, estão diretamente relacionadas aos espaços de EPS.

Estudos apontam a importância, na área da saúde mental, que a EPS considere as experiências cotidianas dos trabalhadores (Santos \& Vecchia, 2016; D. L. S. Silva \& Knobloch, 2016), bem como as relações de produção de cuidado nos equipamentos de saúde mental, estabelecidas entre os diferentes atores sociais (Medeiros, Nascimento, Pavòn, \& Silveira, 2016). D. L. S. Silva e Knobloch (2016) ressaltam a importância da utilização de metodologias ativas de ensino-aprendizagem que promovam espaços de reflexão respeitando as singularidades de cada serviço.

Tomando como parâmetro o contexto descrito acima, objetivamos apresentar a perspectiva de gestores e profissionais de saúde da Rede de Atenção Psicossocial (RAPS) de Porto Alegre no que diz respeito a como e em que espaços é possível promover EPS.

\section{Método}

O presente artigo foi produzido a partir da tese de doutorado em Psicologia Social denominada Educação Permanente em Saúde: Uma estratégia para transformar práticas em saúde mental. A pesquisa foi realizada com profissionais e gestores da RAPS da Secretaria Municipal da Saúde de Porto Alegre. Trata-se de um estudo de abordagem qualitativa (Minayo, 2010), em que buscamos compreender a realidade através da história, das relações, representações, crenças, percepções e opiniões produzidas pelas pessoas. A pesquisa qualitativa está, portanto, situada num determinado tempo histórico "com toda a relatividade que o dinamismo do processo social requer" (Minayo, 2010, p. 47). 
Para a efetivação da pesquisa, foram entrevistados 24 (vinte e quatro) sujeitos que atuam na Rede de Atenção Psicossocial, sendo oito gestores, oito profissionais vinculados a serviços especializados em saúde mental e oito profissionais que desempenham suas funções na atenção básica em saúde. O tempo médio de trabalho no SUS foi de 14 (quatorze) anos e, na atual função, foi de 5 (cinco) anos. Os participantes foram selecionados por conveniência. O critério para a escoIha dos profissionais foi ter participado de pelo menos uma atividade relacionada à EPS, tais como seminários, rodas de conversa ou reuniões de avaliação e/ou de discussão dos processos de trabalho, no período de agosto de 2013 a dezembro de 2014, promovida pela Secretaria Municipal da Saúde. Assim, os profissionais foram convidados a participar da pesquisa durante uma das atividades anteriormente descritas.

As entrevistas semiestruturadas foram gravadas e transcritas literalmente. Fizeram parte do roteiro de entrevista questões acerca da concepção de EPS; como a EPS se inseria no cotidiano de trabalho em saúde; e relação entre EPS e processos de trabalho. Para apreciação do material, utilizamos a análise temática (Braun \& Clarke, 2006). Os passos seguidos no procedimento de análise temática foram: a) transcrição das entrevistas; b) codificação inicial dos temas mais relevantes sobre EPS; c) escolha e definição dos temas relacionados; d) releitura e recodificação das entrevistas; e) interpretação e organização dos dados; f) redação da análise de dados interligando narrativa analítica e extratos ilustrativos que foram fornecidos no texto. A partir das respostas obtidas, foi possível elaborar um conjunto de dados, que foram organizados nas categorias em COMO e em que ESPAÇOS se produz EPS, que serão analisados a seguir.

Os participantes assinaram o Termo de Consentimento Livre e Esclarecido (TCLE) e os critérios éticos foram respeitados, de acordo com Resolução em Pesquisa com Seres Humanos do Conselho Nacional de Saúde (Resolução n 466/2012). Os nomes dos entrevistados são fictícios, preservando a identidade dos mesmos. O estudo foi aprovado pelos Comitês de Ética em Pesquisa da PUCRS e da Prefeitura Municipal de Porto Alegre, com parecer número 772.469/2014.

\section{Como e em que Espaços se Produz Educação Permanente em Saúde}

As categorias como e em que espaços se transversalizam pois, ao falar em como, invariavelmente nos remetemos aos espaços em que se realiza EPS, segundo a concepção dos entrevistados. Como fazer se configura em algum espaço, seja ele concreto, simbólico ou engendrado a partir das necessidades de determinada circunstância. Assim, o como nos diz sobre modos de fazer e de promover Educação Permanente e o espaço nos remete a uma configuração que reflete a dinâmica que o produziu. Capacitações, cursos, seminários, reuniões de equipe, matriciamento, cotidiano dos serviços e fóruns da RAPS sintetizam os dados que os profissionais referiram nas categorias espaço e como se produz EPS.

\section{Capacitações, Cursos e Seminários}

Os resultados acerca da perspectiva dos profissionais sobre como e em que espaços se produz EPS apontam para capacitações, cursos e seminários que contemplem as demandas dos serviços. Esse aspecto revela que a concepção de como fazer ainda está vinculada à formação profissional realizada em espaços formais e planejados para tal. Contudo, os profissionais associam a importância da formação aliada às necessidades cotidianas do trabalho em saúde mental, o que demonstra a possibilidade de construir a interface entre capacitações e EPS ao unir conhecimento técnico e a reflexão sobre o que esse conhecimento pode produzir na prática específica de cada contexto. A possibilidade de adquirir, ampliar ou mesmo de revisitar os conhecimentos técnicos através de capacitações pode favorecer a abertura de brechas nos modos de fazer saúde e produzir problematização acerca das práticas e, com isso, impulsionar a inserção da EPS no cotidiano do trabalho. Uma profissional refere em sua entrevista:

[...] eu entendo que educação permanente é estar formatando as capacitações a partir da necessidade e da demanda que chega, tanto dos serviços quanto dos trabalhadores. (Emília, gestora)

Para outro profissional os cursos e capacitações, além de proporcionarem conhecimentos técnicos, levam a refletir sobre o trabalho e avaliar os resultados do que está sendo feito:

[...] os cursos, eles ajudam muito, pontuando quais as coisas mais importantes [...]. É importante a gente estar se atualizando, fazendo cursos, para poder não só melhorar os conhecimentos que a gente tem, mas também para aprender coisas juntos. (Silvio, atenção especializada)

Na EPS a aprendizagem é construída também na possibilidade do erro, na medida em que as circunstâncias das práticas muitas vezes são problematizadoras do saber ou da técnica instituída. J. A. M. 
Silva e Peduzzi (2011) apontam a importância da educação em saúde atrelada às necessidades dos serviços, corroborando para a articulação dos saberes e práticas, assim como para a ampliação do conceito de saúde. Em pesquisa realizada acerca do trabalho e educação em saúde, as autoras referem que as atividades educativas são inerentes ao trabalho em saúde, reforçando o caráter complementar entre Educação Continuada e Educação Permanente em Saúde. Na perspectiva da Educação Continuada, que pode ser parte da EPS, mas não restrito a ela, encontram-se as atividades realizadas através de ações educativas, sob uma ótica tradicional, na qual a informação é transmitida por alguém que detém conhecimento técnico, instrumentalizando os participantes. Na EPS, situa-se a perspectiva "de reflexão sobre as práticas de saúde com a participação dos trabalhadores, usuários e gerentes para a construção coletiva de novos saberes" para realização do trabalho em saúde (J. A. M. Silva \& Peduzzi, 2011, p. 1029).

Desse modo, as ações de capacitação não podem estar descontextualizadas do cotidiano dos serviços e precisam atender as demandas que os profissionais apontam como relevantes para o processo de trabalho, ou seja, precisam ter como foco o trabalho e sua interface com as demandas dos usuários, respeitando as diferenças locorregionais, como aponta uma entrevistada:

[...] na educação permanente é ter espaços que não sejam espaços isolados, ter espaços de trazer temáticas pertinentes, de poder estar oferecendo ao nosso grupo de trabalhadores um pouco das demandas que a gente identifica pelas dificuldades que eles nos trazem [...]. E por isso eu acredito muito na educação permanente regional. (Débora, gestora)

A aproximação com as realidades locais favorece para que a EPS possa ser uma estratégia facilitadora para leitura dos contextos nos quais os serviços de saúde estão inseridos e, no decorrer do percurso, provocar modificações no cuidado em saúde mental sintonizadas com a Reforma Psiquiátrica. Os espaços de capacitação, muito destacados pelos entrevistados, podem ser uma ferramenta-ponte para que os profissionais reflitam sobre o processo de trabalho ao mesmo tempo em que agregam conhecimentos técnicos. Nessa dinâmica, que relaciona como e espaço, percebe-se o propósito de chegar aos pressupostos da EPS, ou seja, colocar o cotidiano de trabalho em análise, possibilitando "a reflexão e avaliação de sentido dos atos produzidos" (Ceccim, 2005b, p. 161).

Capacitação técnica e EPS seguem juntas no cenário de trabalho em saúde mental, fomentando práticas comprometidas com o cuidado integral, promotoras de autonomia para os usuários e de sentido para os profissionais. Uma não exclui a outra; ao contrário: agregadas, podem potencializar as mudanças e fortalecer as diretrizes da Reforma Psiquiátrica de modo a resgatar e ampliar os direitos das pessoas excluídas do convívio social e estigmatizadas pela circunstância de ter um sofrimento psíquico. Nesse sentido, a inserção da EPS nas atividades rotineiras dos serviços de saúde é uma estratégia para que ela se constitua em espaços transformadores nos quais se estabeleçam relações propositoras de processos em permanente movimento.

\section{Reuniões de Equipe}

Um espaço apontado pelos profissionais entrevistados é a reunião de equipe, atividade que faz parte da rotina de trabalho e que também se refere a como fazer EPS.

[...] abrir espaço para reunião de equipe, até as pessoas entenderem que a reunião de equipe pode ser, por si só, um processo de educação permanente, começar criando um espaço [...] e ir incorporando esse modo de pensar nas atividades mais rotineiras assim do dia a dia. (Julia, atenção especializada)

A reunião de equipe, além dos aspectos administrativos e informativos que a caracterizam, tem o propósito de ser um espaço de discussão e reflexão sobre o cotidiano de trabalho e os aspectos que envolvem os fazeres em saúde (D. L. S. Silva \& Knobloch, 2016). A composição da equipe por seus diferentes profissionais com concepções, crenças, conhecimentos e habilidades que diferem entre si, pode favorecer a interface entre os participantes. Contudo, é importante que o espaço de reunião de equipe possa ser um lugar de debates participativos, de ampliação da capacidade de escuta e de diálogo, de construção coletiva de possibilidades, levando a equipe à produção de autonomia e reinvenção do processo de trabalho em saúde. É na potência dos encontros que os conflitos e os desafios estão postos e que convocam a equipe para o fazer coletivo, com os profissionais apoiando-se mutuamente, compartiIhando conhecimentos e práticas. Sobre esses aspectos, a entrevistada Joana refere: 
[...] no momento que eu trago um caso para equipe, que a gente discute o caso, que um pensa de um jeito, ou outro pensou de outro e a gente entra num consenso de fazer com aquela família, com aquele paciente, isso é uma educação permanente para mim. (Joana, atenção básica)

Como e em que espaços se produz EPS tem uma relação direta nesse contexto, na medida em que os profissionais que compõem o espaço favorecem o como e vice-versa, contribuindo para que a equipe possa "conquistar a capacidade de ser seu próprio coautor de um processo de reinvenção das instituições e do mundo do trabalho", como escreve Merhy (2013, p. 592). No campo da saúde mental, as transformações passam necessariamente pelos profissionais que compartilham o cotidiano dos serviços, pois são eles que administram o cuidado e buscam sentido para as práticas que realizam (Santos \& Vecchia, 2016; D. L. S. Silva \& Knobloch, 2016). Nesse contexto, a EPS pode encontrar espaço na reunião de equipe, envolvendo profissionais como um "coletivo vivencial", segundo expressa a profissional Vitória, ao referir que "[...] educação permanente é necessariamente envolver o serviço cotidiano, o dia a dia e o coletivo vivencial [...] é o tempo todo, até uma reunião de equipe." (Vitória, atenção especializada)

No trabalho em equipe os profissionais precisam negociar e construir de "modo compartilhado os projetos de cuidado, que estão sempre em disputa" (Merhy, 2013, p. 592). Disputa posta pela diversidade de práticas, de conhecimentos e concepções que compõem o mundo do trabalho em saúde. As intercessões dos encontros reverberam em práticas que dizem sobre os modos de fazer das equipes, atualizados constantemente no processo de trabalho. No fragmento da entrevista de Julia, a profissional aponta sobre o espaço e como a EPS pode ser realizada:

Em reuniões de equipe [...] é um processo onde a educação permanente sem dúvidas se insere [...], porque é uma forma de debater, de questionar, de trazer um corpo de conhecimentos, de rever isso, de ver a opinião, a impressão das pessoas e é um instrumento de reajuste, de modificação. (Julia, atenção especializada)

A complexidade das demandas de saúde, especificamente no caso de saúde mental, requer cada vez mais, por parte dos profissionais, a capacidade de pensar criticamente as práticas e os modos de conceber e fazer saúde (D. L. S. Silva \& Knobloch, 2016). Complexidade, no sentido etimológico da palavra, significa "tecer em conjunto", o que nos remete a encontros, conforme aponta Scarparo (2009). Os encontros podem desencadear processos de "criação coletiva e contínua", favorecendo a reflexão crítica acerca dos processos de formação, pesquisa e intervenção no campo da saúde (Scarparo, 2009, p. 135-6).

A complexidade que envolve a atenção em saúde mental precisa ser tomada como um desafio a ser trabalhado desde a graduação profissional, perpassando as práticas nos serviços e no trabalho em equipe, de maneira a ampliar a noção de cuidado para além da psicopatologia. É um desafio na medida em que colocamos em xeque modos instituídos de fazer e conceber saúde mental e também ao nos abrirmos para engendrar outras possibilidades de cuidado, para além do modelo biomédico. Ou seja, exercitar modelos que possam romper com a fragmentação entre saberes e práticas em saúde, contrapondo os reducionismos e a "objetivação dos sujeitos" (Ministério da Saúde, 2010, p. 16). Todavia, as equipes também são espaços de manutenção do instituído. Segundo Lourau (2004), instituído se refere a ordem, aos modos de representação e valores vigentes, considerados normais e aceitos institucionalmente. Isso se evidencia nas resistências que se manifestam diante da probabilidade de mudanças ou mesmo através de disputas no âmbito dos conhecimentos técnicos ou relacionais. Porém, é a partir de uma postura de permanente aprendizagem que o instituído pode ser interrogado e desconstruído, diluindo as resistências e dando chance à diversidade de composições de práticas e conhecimentos, como nos diz Sofia: Porque tu tens que desconstruir algumas coisas na equipe e construir outras, aí tu precisas das pessoas. A gente cuida junto, né? (Sofia, atenção básica)

A partir das entrevistas, podemos presumir que as reuniões de equipe têm se mostrado como espaços-territórios amplamente capazes de associar, articular, problematizar e, por meio desses processos, levar os profissionais a se desacomodarem e a (re)pensarem os fazeres em saúde, ou seja, o como. Nessa interação espaço-como, apontado pelos profissionais entrevistados, é que a potência da EPS se evidencia, ampliando possibilidades para reconfigurar o cuidado em saúde mental.

\section{Matriciamento}

O matriciamento acontece a partir de trocas teóricas e práticas entre a equipe de referência (equipe de atenção básica à saúde que acompanhará a posteriori os casos de forma longitudinal) e a equipe matricial (equipe de profissionais do nível de atenção 
especializada). Segundo Campos (2012), o matriciamento oferece uma atenção singular ao usuário, que respeita as diferentes culturas e necessidades de cada território e de cada equipe de referência.

Os profissionais entrevistados destacam as ações de matriciamento como um dos espaços possíveis de realizar EPS, pois a interlocução que esses encontros produzem pode levar à problematização das práticas e conhecimentos no campo da saúde, bem como às mudanças no processo de trabalho. Renato retrata que sua experiência com o matriciamento tem favorecido o aprendizado e o interesse por conhecer outras perspectivas: "[...] ]a partir do momento em que você tem um profissional que está disposto a analisar os casos contigo, matriciar com você [...] a gente aprende muito com essas discussões porque surgem casos dos outros colegas que vão matriciar também." (Renato, atenção básica)

Por se tratar de uma proposta pedagógica, o matriciamento pode ser entendido como uma das possibilidades de desenvolver EPS, segundo profissionais entrevistados para este estudo. É nessa interação entre os profissionais de diferentes áreas, mas em princípio com interesses comuns - a atenção aos usuários de saúde mental - que o espaço de matriciamento tem favorecido o diálogo entre os profissionais do nível especializado com a atenção básica, ampliando a troca e a produção de conhecimentos sobre as pessoas com sofrimento psíquico. A profissional que participa do matriciamento refere:

[...] quando eu comecei a fazer matriciamento, percebi a resistência e a dificuldade que muitas equipes tinham de aceitar essa proposta [...] E à medida que esse processo foi acontecendo, aos poucos foi evoluindo. As pessoas hoje sentem falta desse instrumento [...]. Então, por um lado isso, uma transformação nesse sentido de poder de certa forma flexibilizar o funcionamento das pessoas. Uma coisa que tinha um jeito mais rígido, mais engessado, agora se torna permeável, se torna mais passível de troca. E por outro lado, na prática mesmo, pessoas aprendem coisas, levam para outros o seu reconhecimento nesse processo de troca, comparam, reformulam a forma de trabalhar, de agir, de funcionar. (Julia, atenção especializada)

A construção compartilhada do cuidado em saúde mental extrapola o âmbito do especialismo e avança para os territórios onde as pessoas vivem, reforçando as unidades de saúde como referência e a atenção situada com as realidades locais. A proximidade com as especificidades e necessidades das pessoas, o vínculo e a relação que se estabelece entre profissionais e usuários são componentes essenciais para a promoção de intervenções terapêuticas em saúde mental. Assim como destacam Hirdes e Scarparo (2015), o matriciamento pode ser considerado como e um dos espaços para realizar EPS, visto que é uma metodologia de trabalho que depende das relações entre os diferentes atores sociais envolvidos no processo de cuidado e possibilita a ampliação dos cenários onde se realiza a atenção especializada.

Nesta mesma direção, Campos (2012) propõe que os espaços de matriciamento possam ser dialógicos, favorecendo a cogestão dos processos de cuidado e trazendo para análise a assimetria, que é constitutiva das relações entre as pessoas. A assimetria e as diferenças, segundo o autor, precisam ser evidenciadas e trabalhadas nas equipes, tornando viáveis respostas articuladas para as necessidades de saúde. Aqui, identificamos a potência do matriciamento para a conquista da postura de EPS na medida em que passamos a problematizar e a colocar em evidência os modos de operar o cuidado em saúde, as diferenças que fazem parte das relações entre profissionais e também a relação com os usuários.

A EPS tem como pressuposto a aprendizagem que abrange a prática diária dos profissionais, estabelecendo uma relação direta entre o que é vivenciado e o que isso pode significar na construção do cuidado em saúde. Esse viés rompe com a lógica tradicional de procedimentos técnicos estabelecidos de antemão e remetem para a singularização dos processos de cuidado, construídos de maneira compartilhada (Lírio, 2016) e que tenham sentido tanto para os profissionais quanto para os usuários. Esse é um dos inúmeros desafios da atenção em saúde mental, pois reforça o protagonismo dos usuários e trabalhadores nos processos de cuidado e instiga o estabelecimento de relações horizontais, permeadas por afetos, contradições, interesses e sentidos diversos.

\section{Cotidiano dos Serviços}

"Educação Permanente é coisa do dia a dia [...]; a gente faz EPS quase que a todo momento dentro do serviço." (Beatriz, atenção especializada)

O cotidiano dos serviços de saúde foi apontado pelos participantes da pesquisa como e um dos espaços para promover EPS, como exemplificado no fragmento da entrevista de Beatriz. O cotidiano do trabaIho em saúde mental é permeado por respostas que os 
profissionais oferecem diante das demandas dos usuários. Para Spink (2008), o cotidiano

nada mais é que um fluxo de fragmentos corriqueiros e de acontecimentos em micro lugares[...]. Os micro lugares e seus diferentes horizontes são produtos e produtores de vários processos sociais e identitários: nós, eles, os temas a serem debatidos, com quem conversamos, como e onde vivemos (p. 70-71).

A definição do autor nos remete a processos dinâmicos e interativos que nos levam a compartilhar os espaços do cotidiano dos territórios existenciais. É nesse cotidiano, marcado por necessidades de diferentes ordens e por ações de cuidado, que os profissionais se encontram e operacionalizam o "trabalho vivo em ato" (Merhy \& Franco, 2003, p. 6). O trabalho vivo pressupõe "encontro com o outro e que só existe nesse momento, no ato, sem o qual deixa de existir", como reafirma Merhy (2013, p. 588). É no contexto e na proximidade das ações realizadas no cotidiano que a EPS encontra brechas para se inserir e abrir possibilidades de problematizar, repensar e rever os processos de trabalho em saúde. A entrevistada Miriam refere: "Educação Permanente para mim é fazer essa atividade dentro do cotidiano [...] dentro do teu local [...], porque eu acho que é onde se produz o trabalho e onde vão aparecer todas as especificidades, os problemas, as dificuldades." (Miriam, gestora)

O trabalho em saúde requer, muitas vezes, que o profissional revise seu modo de atuar, de acolher certas demandas ou mesmo seu próprio conhecimento técnico. No âmbito da saúde mental isso é estratégico, visto que a reconfiguração da atenção tem sido um ponto crucial para avançarmos nas diretrizes políticas da Reforma Psiquiátrica. Nesse cenário, colocar em questão como se produz cuidado em saúde mental na rede de serviços é imprescindível para transformar processos instituídos e cronificados de fazeres e saberes. Esse processo é efetivo na medida em que está atrelado às práticas cotidianas dos serviços, aos territórios existenciais onde a vida e o cuidado acontecem e onde as ações de saúde podem adquirir sentido para os profissionais. Mas nem todos os profissionais aceitam as mudanças, como destaca Vitória na sua entrevista: "A saúde é mais conservadora [...]. Acho que isso acaba comprometendo muito o trabalho [...]. Acho que é resistência à mudança, né, insegurança." (Vitória, atenção especializada)

Mudanças podem gerar resistências e, como já referimos, modificar os processos cotidianos de trabalho em saúde mental é um desafio permanente, pois incita os profissionais a olhar para as práticas cristalizadas e problematizá-las. Através da EPS, podemos vislumbrar estratégias para problematizar e revisitar o espaço cotidiano dos profissionais que apresentam resistências e insegurança, como aponta Vitória: "[...] para intervir no processo de equipe, para trabalhar as relações [...] poder mudar lá, tem que incidir sobre aquele ambiente." (Vitória, atenção especializada)

Reforçando a estratégia da EPS através da problematização, Emília refere: "A Educação Permanente, resumindo, é a partir da problematização do meu trabalho, lá no meu dia a dia." (Emília, gestora)

A dimensão do trabalho cotidiano em saúde é referida por J. A. M. Silva e Peduzzi (2011) como "microssocial", pois "diz respeito ao exercício cotidiano do trabalho, aos sujeitos e à intersubjetividade, ou seja, à prática dos trabalhadores no cotidiano da produção $\mathrm{e}$ do consumo de serviços de saúde" (p. 1020). O trabaIho em saúde mental é, em ampla medida, relacional, marcado pelos encontros entre trabalhadores e usuários, reforçando a intersubjetividade e inevitavelmente "dotado de incertezas e descontinuidades", sendo impossível padronizar as atividades que serão realizadas, como destacam Lima et al. (2010, p. 208).

Assim, o cotidiano dos serviços de saúde, pelas especificidades que o caracterizam, apresenta-se como e um dos espaços em que é possível a realização de EPS, pois está conectado com as realidades locais e reflete as necessidades físicas e simbólicas que os profissionais vivenciam. Isso nos remete a movimentos constantes, às dinâmicas que nos movem e nos tiram da inércia, tão característica da cronificação. O inesperado que vivemos nos espaços cotidianos dos serviços de saúde se apresenta como desafio que nos indica que a vida acontece no aqui e agora, na conjugação do presente. Ao mesmo tempo, o inesperado nos provoca a pensar na articulação entre as especificidades da saúde mental e às generalidades que cuidado integral requer (Scarparo, Leite, \& Santos, 2013).

\section{Fóruns da Rede de Atenção Psicossocial}

Outra referência a como e em que espaços se realiza EPS, feita pelos profissionais entrevistados, foram os Fóruns da Rede de Atenção Psicossocial (FRAPS). Os fóruns são encontros mensais que reúnem profissionais dos diferentes pontos da RAPS dos territórios da cidade. Têm como objetivos promover a interlocução entre os serviços, ampliar a interface para realização de ações de cuidado, estabelecer fluxos, discutir processos 
de trabalho e fomentar ações de EPS nos territórios. Trata-se de um espaço coletivo de debates éticos, técnicos e políticos, mas também consultivo e deliberativo no âmbito da gestão territorial dos serviços de saúde.

No âmbito da micropolítica do trabalho em saúde, podemos entender os FRAPS como espaços em que se engendram relações, encontros, discussões e possibilidades de criar condições para atenção e cuidado em saúde contextualizados com as necessidades locorregionais, como aponta o fragmento da entrevista de uma gestora:

Eu acho que favoreceu para nossas equipes, principalmente quando iniciou as reuniões da RAPS. A gente estava com um problema de definir exatamente o modelo de atenção de mental em saúde na região. [...]. E modificar algumas práticas, porque estávamos vendo que aquela forma não estava dando resultados. (Patrícia, gestora)

Nesses espaços, a EPS torna-se possível na medida em que coloca em diálogo os diferentes atores do campo da saúde, favorecendo com que apareça o contraditório, aspecto inerente à composição dos espaços coletivos. Essa dimensão do processo de trabalho oportuniza a construção de respostas possíveis, mediadas e acordadas entre os profissionais que compõem o FRAPS. Segundo Ceccim e Merhy (2009) "são os encontros de atores com atores, a partir de seus planos de existência, que dão substancialidade para o campo da política em qualquer cotidiano" (p. 5). Emília aponta para a importância dos espaços coletivos como os FRAPS para propiciar a interação entre os profissionais, assim como para produção de mudanças no campo da saúde: "Eu acredito nos espaços coletivos, acho que eles são fundamentais [...]; espaço de dialogar, de conhecer as pessoas que está nos serviços, se escutar e acaba tendo outro efeito no sentido do trabalho." (Emília, gestora)

Para Dorigan (2013), os objetivos prioritários do trabalho em saúde devem ser a produção de saúde e a construção coletiva entre os diferentes atores sociais, trabalhadores, usuários e gestores. Nesse sentido, os FRAPS são espaços coletivos em que as equipes podem interferir na produção das práticas de saúde dos territórios de atuação, pactuando e construindo ações de saúde mental centradas nas necessidades dos usuários, avaliando os recursos disponíveis e tendo como base os conhecimentos e experiências dos diferentes profissionais (Dorigan, 2013).

Para a entrevistada Sandra, os FRAPS são espaços de composição em que é possível aprender e gerar conhecimentos: "[...] eu gosto das coisas que a gente constrói com quem vai fazer e não vêm de cima para baixo [...]. Que nem a gente faz aqui na RAPS, cada um tem suas coisas e a gente vai indo e construindo aos poucos, gerando aprendizados." (Sandra, atenção básica)

A partir das experiências individuais e coletivas e da problematização das questões que os profissionais trazem no FRAPS, são identificadas as dificuldades e quais as estratégias de intervenção que serão compartilhadas entre os componentes da RAPS. É importante destacar que é ao tecer possibilidades nos espaços coletivos, como os FRAPS, que a saúde mental pode se potencializar e se capilarizar para os territórios de pertencimento existencial das pessoas com sofrimento psíquico, ampliando o cuidado em rede e rompendo com o estigma que envolve essas pessoas. Nesse sentido, a EPS se configura nos espaços do FRAPS como uma importante ferramenta de trans-formação.

\section{Considerações finais}

A EPS é um processo dinâmico e que ganha existência ao se constituir como parte de lugares e fazeres do cotidiano das práticas em saúde. Desse modo, a EPS pode ser realizada através das/nas capacitações, seminários, reuniões de equipe, matriciamento e fóruns de serviços. Todos esses espaços-como remetem a diálogos e a relações que articulam histórias, desejos, práticas e saberes. Envolvem diferentes pessoas e suas distintas concepções e maneiras de viver. Os espaços apontados pelos profissionais têm como característica comum a possibilidade de serem espaços de compartilhamento de saberes e fazeres, de construção coletiva e de aprendizado. Esses espaços podem promover conexões entre os diferentes participantes, reforçando diálogos e a articulações através do como fazer.

A dinâmica interacional entre espaços e como induz a movimentos constantes e ganha potência na medida em que conecta práticas com conhecimento técnico e se capilariza para outros espaços e diferentes como fazer. Nessa perspectiva interacional, provocada no engendramento de espaços-como, consideramos a EPS uma importante estratégia para os profissionais da saúde colocarem em questão seus modos de fazer cotidianos, a olhar para si e se deixarem tocar pelo que percebem, criando possibilidades para produção de saberes vivos. Saberes que poderão se transformar em ações de cuidado integral e focados nas necessidades das pessoas que requerem atenção em saúde. 
Contudo, não é possível fixar e prescrever modos e lugares para fazer EPS, pois há uma infinitude de possibilidades de espaços-como que compõem o dia a dia do trabalho em saúde. A reinvenção de outras possibilidades tem como pressuposto nos tirar do lugar estático do saber-fazer, provocar desacomodação e nos levar a sermos aprendizes na perspectiva do fazer para saber, desterritorializando o instituído e questionando as posturas cristalizadas. Nesse caminho cruzamos com a EPS que nos mostra que nada está pronto ou saturado e que o conhecimento não se aplica, mas vive-se, experimenta-se, e, ao viver, conhecemos, sentimos e nos movemos para outras direções.

Para avançarmos no campo das políticas públicas de saúde mental, acreditamos que a EPS não pode se vincular à noção de permanência, como algo que tem estabilidade ou regularidade. Entendemos que EPS é movimento impermanente e que não pode parar ou ancorar em alguns espaços ou comos, pois a impermanência pressupõe multiplicidade, é cambiante e aberta a possibilidades. Não podemos correr o risco de institucionalizar a EPS espaços-como permanentes, especialmente vinculados a uma metodologia tradicional de aquisição de conhecimentos, pois não há receitas prontas. Na perspectiva da EPS, a aprendizagem acontece na relação com e entre pessoas e acontecimentos, vivenciando as possibilidades em espaços-como diversificados, impermanentes e que podem levar a transformar as práticas em saúde mental.

Acreditamos que outros estudos são necessários para avançar na compreensão e na problematização da EPS no contexto do cuidado em saúde mental, especialmente no que diz respeito a como e em que espaços é possível realizá-la. Estudos que possam favorecer a impermanência pelo diálogo, considerando a EPS como um processo em movimento de re-des-construção, aberto a infinitas possibilidades de modos e lugares de se produzir.

\section{Referências}

Aguiar, K. F., \& Rocha, M. L. (2007). Micropolítica e o exercício da pesquisa-intervenção: referenciais e dispositivos em análise. Psicologia, Ciência e Profissão, 27(4), 648-663. doi: 10.1590/ S1414-98932007000400007

Amarante, P. (2007). Saúde mental e atenção psicossocial. Rio de Janeiro: Fiocruz.

Amarante, P., Oliveira, M. H. B., Torre, E., \& Coelho, I. (2016). Derechos Humanos y Salud Mental en Brasil: uma historia de lucha y militancia por la justicia social y el derecho a la vida - "la salud no se vende, la locura no se encierra". Átopos: Salud Mental, Comunidad y Cultura, 2, 1-16. Recuperado de http://www.atopos.es/images/ eatopos2/4.pdf
Braun, V., \& Clarke, V. (2006). Using thematic analysis in psychology. Qualitative Research in Psychology, 3(2), 77-101. doi 10.1191/1478088706qp063oa

Campos, G.W. S. (2012). Apoio matricial e práticas ampliadas e compartilhadas em redes de atenção. Psicologia em Revista, 18(1), 148-168. doi: 10.5752/3851

Ceccim, R. B. (2005a). Educação Permanente em Saúde: descentralização e disseminação da capacidade pedagógica na saúde. Ciência \& Saúde Coletiva, 10(4), 975-986. doi: 10.1590/ S1413-81232005000400020

Ceccim, R. B. (2005b). Educação Permanente em Saúde: desafio ambicioso e necessário. Interface, 9(16), 161-177. doi: 10.1590/ S1414-32832005000100013

Ceccim, R. B., \& Merhy, E. E. (2009). Um agir micropolítico e pedagógico intenso: a humanização entre laços e perspectivas. Interface, 13(supl. 1), 531-542. doi: 10.1590/S1414-32832009000500006

Delgado, P. G. G. (2011). Democracia e reforma psiquiátrica no Brasil. Ciência \& Saúde Coletiva, 16(12), 4701-4706. doi: 10.1590/ S1413-81232011001300019

Dorigan, J. H. (2013). Fóruns colegiados de saúde mental de Campinas: o caso da rede mista à luz da análise institucional. In S. L'abbate (Org.), Análise Institucional \& Saúde Coletiva (pp. 560-576). São Paulo: Hucitec.

EPS em movimento (2014). Usuário guia. Recuperado de http://eps. otics.org/material/entrada-experimentacoes/usuario-guia.

Haesbaert, R. (2014). Territórios em disputa: desafios da lógica espacial zonal na luta política. Campo-Território: Revista de Geografia Agrária, 9(18), 1-17. Recuperado de http://www.seer.ufu.br/index. php/campoterritorio/article/view/27063/14690

Harvey, D. (2007). Condição Pós-Moderna (16 edição). São Paulo: Edições Loyola.

Hirdes, A., \&. Scarparo, H. (2015). O labirinto e o minotauro: saúde mental na Atenção Primária à Saúde. Ciência \& Saúde Coletiva, 20(2), 383-393. doi:10.1590/1413-81232015202.12642013

Lei n. 10.216, de 6 de abril de 2001 (2001, 6 de abril). Dispõe sobre a proteção e os direitos das pessoas portadoras de transtornos mentais e redireciona o modelo assistencial em saúde mental. Diário Oficial da União, seção 1.

Lima, J. V. C., Turini, B., Carvalho, B. G., Nunes, E. F. P. A, Lepre, R. L., Mainardes, P., \& Cordoni Junior, L. (2010). A Educação Permanente em Saúde como estratégia pedagógica de transformação das práticas: possibilidades e limites. Trabalho, Educação e Saúde, 8(2), 207-227. doi: 10.1590/S1981-77462010000200003

Lírio, A. P. S. (2016). O lugar do sensível na educação permanente em saúde: ausência, continuidade ou ruptura. Cadernos de Educação, Tecnologia e Sociedade, Inhumas, 9(3), 375-38. doi: 10.14571/cets. v9.n3.375-383

Lourau, R. (2004). O instituinte contra o instituído. In S. Altoé (Org.), René Lourau: analista institucional em tempo integral (pp. 47-65). São Paulo: Hucitec.

Macedo, J. P., Abreu, M. M., Fontenele, M. G., \& Dimenstein, M. (2017). A regionalização da saúde mental e os novos desafios da Reforma Psiquiátrica brasileira. Saúde e Sociedade, São Paulo, 26(1), 155170. doi: 10.1590/s0104-12902017165827

Medeiros, G. T., Nascimento, F. A. F., Pavón, R. G., \& Silveira, F. A. (2016). Educação Permanente em Saúde: relato de experiência. 
Interface Comunicação, Saúde, Educação. 20(57): 475-83. doi: 10.1590/1807-57622015.0232

Merhy, E. E. (2013). A organização não existe. A organização existe: uma conversa da micropolítica do trabalho, da educação permanente e da análise institucional. In S. L'Abbate (Org.), Análise Institucional \& Saúde Coletiva (pp. 579-596). São Paulo: Hucitec.

Merhy, E. E., \& Franco, T. B. (2003). Por uma composição técnica do trabalho centrada no campo relacional e nas tecnologias leves. Saúde em Debate, 27(65), 316-323.

Minayo, M. C. S. (2010). O desafio do conhecimento: pesquisa qualitativa em saúde (12a edição). São Paulo: Hucitec.

Ministério da Saúde (2009). Secretaria de Gestão do Trabalho e da Educação na Saúde. Departamento de Gestão da Educação em Saúde. Política Nacional de Educação Permanente em Saúde. Brasília, DF: Ministério da Saúde.

Ministério da Saúde (2010). Secretaria de Atenção à Saúde. Política Nacional de Humanização. Formação e intervenção. Brasília, DF: Ministério da Saúde.

Pessatti, M. P., \& Carvalho, S. R, (2009). Intercessão, arquitetura e saúde e um novo modo de produção do espaço físico na saúde. In S. R. Carvalho, S. Ferigato, \& M. E. Barros (Orgs.), Conexões: saúde coletiva e políticas de subjetividade (pp. 74-93). São Paulo: Hucitec.

Pitta, A. M. F. (2011). Um balanço da reforma psiquiátrica brasileira: instituições, atores e políticas. Ciência \& Saúde Coletiva, 16(12), 4579-4589. doi: 10.1590/S1413-81232011001300002

Portaria $n^{\circ} 1.996$, de 20 de agosto de 2007. Dispõe sobre as diretrizes para a implementação da Política Nacional de Educação Permanente em Saúde e dá outras providências. Brasília, DF: Ministério da Saúde.

Portaria no 3.088, de 23 de dezembro de 2011. Institui a Rede de Atenção Psicossocial para pessoas com sofrimento ou transtorno mental e com necessidades decorrentes do uso de crack, álcool e outras drogas, no âmbito do Sistema Único de Saúde (SUS). Diário Oficial da União, seção 1, 230-232.

Resolução n 466/2012. Diretrizes e Normas regulamentadoras de pesquisa envolvendo seres humanos. Brasília, DF: Conselho Nacional de Saúde. Ministério da Saúde.
Santos, A. P., \& Vecchia, M. D. (2016). Oficina de formação em saúde mental como estratégia de educação permanente em saúde. Saúde \& Transformação Social, 7(2), 69-82. Recuperado de http:// incubadora.periodicos.ufsc.br/index.php/saudeetransformacao/ article/view/4044

Sarreta, F. O. (2012). O trabalho em saúde: desafios da educação permanente em saúde. VII Seminário de Saúde do Trabalhador e VII Seminário "O Trabalho em Debate". Franca/SP: UNESP.

Scarparo, H. (2009). A psicologia social: pesquisa, formação e intervenção. In D. T. Tatsch, N. Guareschi, \& S. Baumkarten (Orgs.), Tecendo Relações e Intervenções em Psicologia Social (pp. 130-138). Porto Alegre: Abrapso Sul.

Scarparo, H., Leite, L. S., \& Santos, S. J. E. (2013). Saúde mental em Porto Alegre: considerações sobre os nossos caminhos. In L. S. Leite, H. Scarparo, M. Dias, \& S. J. E. Santos (Orgs.), Saúde Mental ConVida: registros da trajetória da saúde mental na cidade de Porto Alegre (pp. 140-147). Porto Alegre: Secretaria Municipal da Saúde.

Silva, D. L. S., \& Knobloch, F. (2016). A equipe enquanto lugar de formação: a educação permanente em um Centro de Atenção Psicossocial álcool e outras drogas. Interface -Comunicação Saúde Educação, 20(57), 325-35. doi: 10.1590/1807-57622015.0061

Silva, J. A. M., \& Peduzzi, M. (2011). Educação no trabalho na atenção primária à saúde: interfaces entre educação permanente em saúde e o agir comunicativo. Saúde \& Sociedade, 20(4), 1018-1032. doi: 10.1590/S0104-12902011000400018

Spink, P. K. (2008). O pesquisador conversador no cotidiano. Psicologia \& Sociedade, 20(spe), 70-77. doi: 10.1590/ S0102-71822008000400010.

Tenório, F. (2002). A reforma psiquiátrica brasileira, da década de 1980 aos dias atuais: história e conceitos. História, Ciências, Saúde Manguinhos, 9(1):25-59. doi: 10.1590/S0104-5970200200010

Vasconcelos, E. M. (2012). Crise mundial, conjuntura política e social no Brasil, e os novos impasses teóricos na análise da reforma psiquiátrica no país. Cadernos Brasileiros de Saúde Mental, 4(8), 8-21. Recuperado de http://incubadora.periodicos.ufsc.br/index.php/ cbsm/article/view/2033/2331

Loiva dos Santos Leite, Doutora em Psicologia Social. Pontifícia Universidade Católica do Rio Grande do Sul (PUCRS), é Assessora Técnica em Saúde Mental da Secretaria Municipal da Saúde de Porto Alegre (SMS/PMPA).

Endereço para correspondência: Avenida João Pessoa, 325 - $4^{\circ}$ andar. Porto Alegre, RS. CEP: 90.040-000. Telefones: (51) 998972016 e (51) 32892726 . E-mail: loivaleite.psi@gmail.com

Kátia Bones Rocha, Doutora em Psicologia pela Universidad Autónoma de Barcelona (UAB), Docente do Programa de PósGraduação em Psicologia da Faculdade de Psicologia da Pontifícia Universidade Católica do Rio Grande do Sul (PUCRS) E-mail: katiabonesrocha@gmail.com 